\title{
Bacterial endocarditis involving a subaortic membrane
}

\author{
D Pentousis, J P Cooper, A P Rae
}

Department of

Medical Cardiology,

Glasgow Royal

Infirmary, Glasgow

D Pentousis

J P Cooper

A P Rae

Correspondence to:

Dr D Pentousis, Department

of Medical Cardiology,

Glasgow Royal Infirmary, 10

Alexand

G31 2ER, UK.

Accepted for publication

23 May 1996

\begin{abstract}
A subaortic membrane predisposes to bacterial endocarditis usually affecting the aortic valve and left ventricular outflow tract. Endocarditis involving the subaortic membrane itself has been described twice only; once at operation and once at postmortem. The case of a man with vegetations involving a subaortic membrane that were detected preoperatively and the echocardiographic appearances of these findings are reported.
\end{abstract}

(Heart 1996;76:370-371)

Keywords: subaortic membrane; endocarditis

A 34 year old man complained of mild breathlessness on strenuous exertion and infrequent, left sided chest pain. He had been known to have a cardiac murmur for several years. $\mathrm{He}$ was of normal build. The pulse was regular, with normal character, and the blood pressure was $140 / 75 \mathrm{~mm} \mathrm{Hg}$. Auscultation revealed a harsh systolic murmur over the precordium associated with a palpable thrill as well as a soft, long diastolic murmur of aortic incompetence. The electrocardiogram showed evidence of left ventricular hypertrophy and the chest $x$ ray was normal. Transthoracic and transoesophageal echocardiography demonstrated mild thickening of the right coronary cusp, which was otherwise normal and opening well. There was a subaortic membrane which attached to the chordal apparatus of the anterior mitral valve leaflet. There was significant turbulence in the left ventricular outflow tract and a peak instantaneous pressure gradient of $100 \mathrm{~mm} \mathrm{Hg}$. A jet of mild to moderate aortic regurgitation was present. The appearances were consistent with type II subaortic stenosis (Kelly classification). ${ }^{1}$ The existence of a subaortic chamber was confirmed during cardiac catheterisation, where a peak to peak

Transoesophageal echocardiogram showing irregular thickening of the anterior and posterior aspect of the membrane with frond-like vegetations, about $5 \mathrm{~mm}$ long, protruding from the membrane into the aortic side of the left ventricular outflow tract.

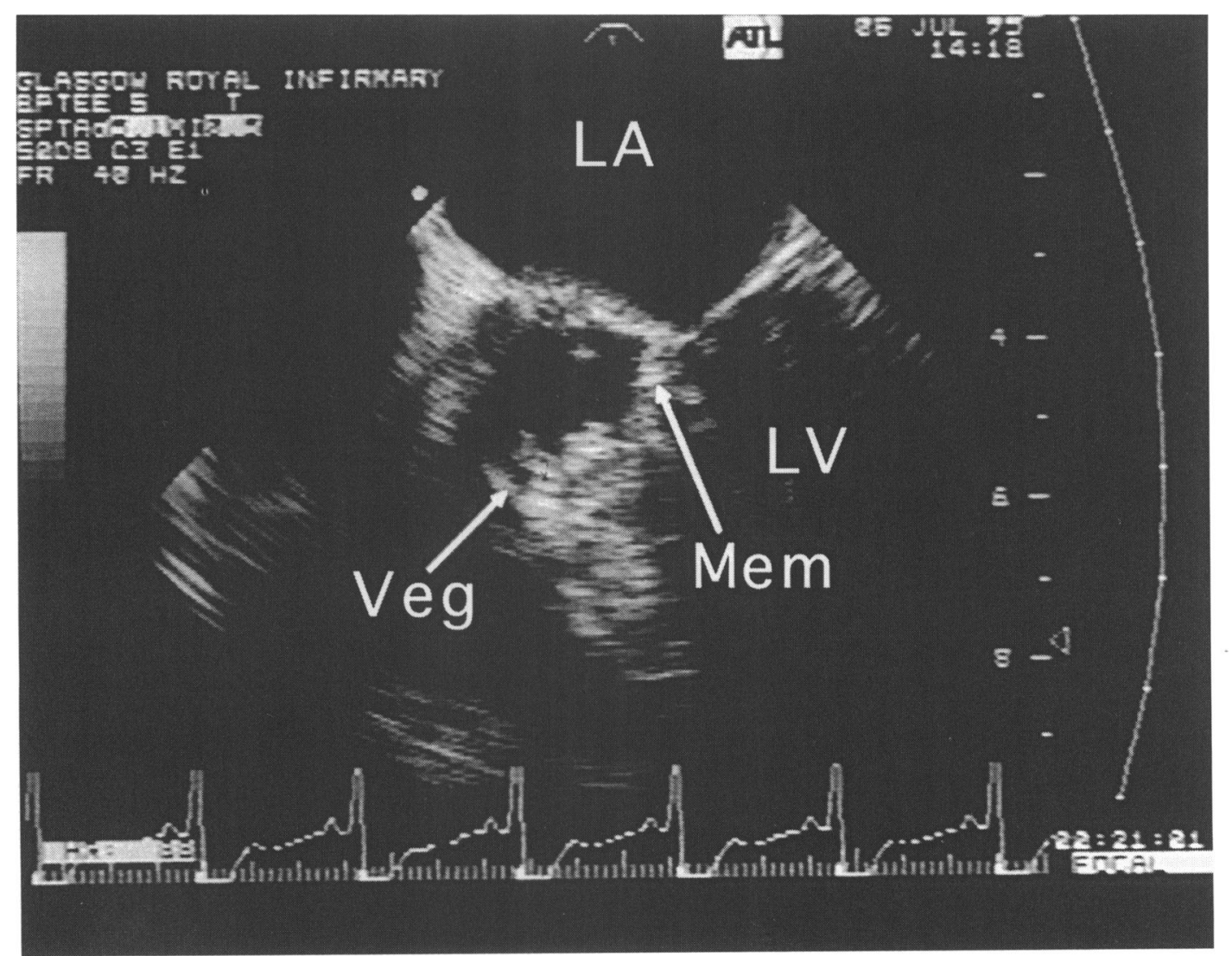


pressure gradient of $90 \mathrm{~mm} \mathrm{Hg}$ was demonstrated.

Elective subaortic membrane resection was scheduled. Before the operation, however, the patient developed night sweats, malaise, loss of appetite, and a dry cough. He was pale and pyrexial with mild splenomegaly but no other signs of bacterial endocarditis. There was no significant change in the characteristics of the murmurs. He had a normochromic, normocytic anaemia (haemoglobin $9 \cdot 1 \mathrm{~g} / \mathrm{dl}$ ), leucocytosis $(21 \times 106 / 1)$, and raised $C$ reactive protein $(167 \mathrm{mg} / \mathrm{l}$, normal range $<10 \mathrm{mg} / \mathrm{l})$. Blood cultures isolated Streptococcus milleri. Transoesophageal examination showed irregular thickening of the anterior and posterior aspect of the membrane with frond-like vegetations, about $5 \mathrm{~mm}$ long, protruding from the membrane into the aortic side of the left ventricular outflow tract (figure). The appearance of the aortic valve was similar to that on the previous echocardiogram.

He was treated with intravenous gentamicin and vancomycin for three weeks with subsequent remission of his infection. He then underwent resection of the membrane. At operation the aortic valve was found to be tricuspid. The right coronary cusp was prolapsing slightly into the ventricle and there was partial commissural fusion with the left coronary cusp. The inferior surface of the valve demonstrated evidence of healed endocarditis. Beneath the valve, about $2 \mathrm{~cm}$ below the annulus, there was a fibromuscular membrane on the anterior part of the septum. This extended to the mitral valve, which now had no obvious macroscopic evidence of endocarditis. The membrane as well as the accessory tissue were excised and the non-coronary cusp was repaired by performing a valvuloplasty. A residual gradient of $40 \mathrm{~mm} \mathrm{Hg}$ remained postoperatively. The patient made an uneventful and full recovery.

\section{Discussion}

We report a case and provide echocardiographic images of a 34 year old patient with a discrete subaortic membrane and vegetations involving the membrane and the left ventricular outflow tract as well as the aortic valve. Early reports emphasised the association of subaortic stenosis and infective endocarditis. ${ }^{23}$ However, endocarditis involving a subaortic membrane specifically has only been con- firmed twice: once at postmortem ${ }^{2}$ and once at operation. ${ }^{4}$ In the combined paediatric series of Kelly et al, ${ }^{1}$ Newfeld et $a l,{ }^{5}$ and Champsaur et $a l^{6}$ there were only two cases of endocarditis in 96 patients with subaortic stenosis, an observation that led to the conclusion that infective endocarditis is not common in this particular patient population. ${ }^{7}$ By contrast, in the series of Shem-Tov et $a l^{8}$ and Wright et $a l^{9}$ of predominantly young patients, infective endocarditis developed in three (14\%) of 21 and 10 $(12 \%)$ of 83 patients respectively. There is a clear correlation between the incidence of endocarditis and increasing age, the presence of aortic regurgitation, the severity of the stenosis, and the existence of other congenital lesions that predispose to infection. ${ }^{29}$ The infectious process almost always originates on the aortic valve, rather than on the obstructing membrane. Although the valve may be normal at birth, the high velocity jet of blood passing through the stenotic subvalvar orifice impinges upon it during systole. The effect of this trauma is to thicken and distort the valve, a finding usually noted during operation in adults but less commonly in younger patients. ${ }^{9}$ These changes may render the valve susceptible to infection which may explain why in all but two patients the findings of endocarditis have been limited to the aortic valve itself. ${ }^{24}$

To our knowledge, this is the first report of vegetations involving a subaortic membrane being detected preoperatively.

1 Kelly DT, Wulfsberg E, Rowe RD. Discrete subaortic stenosis. Circulation 1972;46:309-22.

2 Morrow AG, Fort L, Roberts WC, Braunwald E. Discrete subaortic stenosis complicated by aortic valvular regurgitation. Clinical, hemodynamic and pathologic studies and the results of operative treatment. Circulation 1965; 31:163-71.

3 Fontana RS, Edwards JE. Congenital cardiac disease. $A$ review of 357 cases studied pathologically. Philadelphia: WB Saunders, 1962;219

4 Katz NM, Buckley MJ, Liberthson RR. Discrete membranous subaortic stenosis. Report of 31 patients, review of the literature and delineation of management. Circulation 1977;56:1034-8

5 Newfeld EA, Muster AJ, Milton PH, Idriss FS, Riker WL Discrete subvalvular aortic stenosis in childhood. Study of 51 patients. $A m$ F Cardiol 1976;38:53-61.

6 Champsaur G, Trusler GA, Mustard WT. Congenital discrete subvalvar aortic stenosis. Surgical experience and crete subvalvar aortic stenosis. Surgical experience and
long-term follow-up in 20 paediatric patients. Br Heart $\mathcal{f}$

7 Sung CS, Price EC, Cooley DA. Discrete subaortic stenosis in adults. $A m \mathcal{F}$ Cardiol 1978;42:283-90.

8 Shem-Tov A, Schneeweiss A, Motro M, Neufeld HN. Clinical presentation and natural history of mild discrete subaortic stenosis. Follow-up of 1-17 years. Circulation 1982;66:509-12.

9 Wright GB, Keane JF, Nadas AS, Bernhard WF, Castaneda AR. Fixed subaortic stenosis in the young: medical and surgical course in 83 patients. Am 7 Cardiol 1983;52:830-5. 